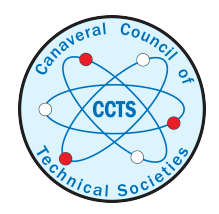

Apr 1st, 8:00 AM

\title{
A Concept For Space Shuttle Payload Ground Operations
}

\author{
Gene McCoy \\ Chief, Payload Integration Office, National Aeronautics and Space Administration, Kennedy Space Center, \\ Florida
}

Follow this and additional works at: https://commons.erau.edu/space-congress-proceedings

\section{Scholarly Commons Citation}

McCoy, Gene, "A Concept For Space Shuttle Payload Ground Operations" (1973). The Space Congress ${ }^{\circledR}$

Proceedings. 2.

https://commons.erau.edu/space-congress-proceedings/proceedings-1973-10th/session-5/2

This Event is brought to you for free and open access by the Conferences at Scholarly Commons. It has been accepted for inclusion in The Space Congress ${ }^{\circledR}$

Proceedings by an authorized administrator of Scholarly Commons. For more information, please contact commons@erau.edu.

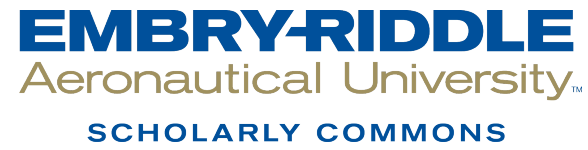


Gene McCoy

Chief, Payload Integration office

National Aeronautics and Space Administration

Kennedy Space Center, Florida

\section{ABSTRACT}

A Space Transportation System that involves the reusable Space Shuttle offers mankind's next great frontier. The country and the NASA must approach this potential opportunity with an open mind for new ideas and concepts in operations management; business principles, and sensitivity to cost.

Our long term future in this new frontier will depend as much on our success in these areas as on our technological successes.

This paper attempts to provide, for people with a working understanding of current ground operations, some examples of these evolving concepts.

\section{THE CONCEPT}

The reusable nature of the Space Shuttle opens a large number of opportunities to reduce the cost and improve the effectiveness of payload operations, Most of these opportumities result directly from the fact that reusable space vehicles have the potential of passing through a test and development phase into an operational phase that is much more similar to an airplane operation than anything in NASA's history.

Let us assume that it is 1985 and we as a nation have an operational shuttle flying 40 to 60 flights per year. Let us take a look at the possible nature of the Kennedy Space Center in that era. The old John F. Kennedy Space Center has passed through a metamorphosis which included the development of an integrated multi-program ground system and has evolved into the center of NASA's "operational" activity. The term "operational" describes an activity involving hardware that has matured beyond the research and development phase and is for the most part comprised of standardized systems and subsystems. The most visible characteristic is its low cost which is often an order of magnitude below that of a similar operation which is RoकD in nature.

Although the Center is basically operational in its nature, it acts as host to numerous space research, development, applications and entrepreneurial programs which comprise a significant proportion of the payloads, for the Shuttle. We notice that NASA has effectively separated the management of its Rog activities from those that it intends to become operational or standardized and realized large cost savings in standardized or "operational" activities. Although total Profit Center Accounting is not yet practical, great strides have been made in that direction.

The broad functions of this NASA facility can be divided into four categories: (Figure 1)

\section{Figure 1}

\section{BROAD FUNCTIONS AT THE SHUTTLE LAUNCH SITE}

- Management of the Space Shuttle "Airline"

- Management of the Space "Airport"

- Payload Operations and Support

- Management of NASA-wide "pools" of operational, standardized, components, subsystems, and interfacing hardware

Since we are particularly interest in payloads, let us $100 \mathrm{k}$ at the functional elements of Payload Operations and Support: (Figures 2 and 3 )

\section{Figure 2}

\section{FUNCTIONAL ELEMENTS OF PAYLOAD OPERATIONS AND SUPPORT}

1. Monitor payload design and development to ascertain compatibility with operational concepts, safety and schedule.

2. Provide guidance to payload owners during their factory acceptance.

3. Perform Host function for all owners of payload elements.

4. Provide counseling to payload element owners on techniques and procedures for flight preparation. 


\section{Figure 3 \\ FUNCTIONAL ELEMENTS OF \\ PAYLOAD OPERATIONS AND SUPPORT}

(Continued)

5. Provide the subsystem expertise on payload systems that are operational and standard.

6. Integrate payload elements into total payloads

7. Demonstrate payload system compatibility with orbiter and facility prior to orbiter mate.

8. Function as the payload owner for NASA payload carriers that are "operational."

9. Perform ground and flight operational training for payload flight crews.

10. Maximize commonality and compatibility with a DoD operation at the Western Test Range.

Let us 100 k briefly at each of the 10 functional elements shown on Figures 2 and 3 :

1. Monitor Payload Design and Development to Ascertain Compatibility with Operational Concepts, Safety and Schedule. This item refers to the responsibility to maintain liaison with the payload developer to provide the operational viewpoint as early as Phase A and to follow-up by ascertaining that the total shuttle/payload mission is optimized.

2. Provide Guidance to Payload Owners During Their Factory Acceptance. Expertise acquired as the NASA's test and launch organization has proven helpful in factory acceptance and eases the transition of payloads from the factory to the operational enviromment. This expertise is utilized in testing for and eliminating various failure modes. This expertise is applied in accordance with mature criteria for risk analysis and risk acceptance. This criteria, for example, precludes the expenditure of 1.2 million dollars to prevent a 1 million dollar failure.

3. Perform Host Function for A11 Owners of Payload Elements. The host function involves providing to the payload owner all the launch site interfaces and support required. The host function also involves ascertaining that the payload operation and the total operation are compatible. Examples of operational elements that must be considered are the Shuttle operation, the total schedules, the facility operation, safety and hardware and operational interfaces. The host concept applies to one of a kind payloads and payloads which are undergoing constant changes and improvements by the developers.
4. Provide Counseling to Payload Element Owners on Techniques and Procedures for Flight Preparation. The Kennedy Space Center has acquired a vast background in rewards and pitfalls of preparing hardware for flight. This counsel draws from that background.

5. Provide the Subsystem Expertise on Payload Systems that Are Operational and Standard. Subsystem expertise exists at the Center for systems that are standard or common to the orbiter or other hardware. This expertise is provided to the payload owner as part of the host function. One concept for management of this operation was developed for NASA-KSC in a 1973 study by TRW.

6. Integrate Payload Elements Into Total Payloads. Many shuttle missions involve numerous payload elements. It is necessary to establish that all of the payload elements that make up a total payload are compatible with each other. This involves analysis or test to establish that they have no functional, thermal, electronic, or mechanical interferences. Examples of payload elements that combine to form a total payload are two expendable third stages with spacecraft.

7. Demonstrate Payload System Compatibility with Orbiter and Facility Prior to Orbiter Mate. This function is necessary because of orbiter mnortunity costs. Delay of an orbiter schedule to troubleshoot a small payload compatibility problem not only involves stoppage of a major portion of the nation's space program but also adds to the runout time and cost for all payloads subsequently assigned to that orbiter. This function is performed with a pre-mate test involving an integrated systems test with orbiter interfaces simulated. For many of the payloads in NASA's mission model, this is the single test accomplished at the launch site prior to orbiter inate.

8. Function as the Payload Owner for NASA Payload Carriers that Are Operational. Once payload elements become operational, the developers turn them over to the "operational" element in the same way that an airliner developer turns the airplane over to the airline. Examples of payloads that have become "operational" are: Standard Experiment Carriers, the Tug, the support module of the Sortie Lab, Expendable Third Stages and the Quick Reaction Sortie Lab as defined in the 1973 IRW study we have already mentioned.

9. Perform Ground and Flight Operational Training for Payload Flight Crews. Flight crews for payload operations arrive from all parts of the world. Their preparation for flight involves a 
brief period of indoctrination on such operational considerations as the physiological effects of zero and multi-g's, emergency procedures, and their relationship with other parts of the flight and ground crew.

10. Maximize Commonality and Compatibility with a DoD Operation at the Western lest Range. The Department of Defense is operating a military shuttle from the West Coast in 1985. NASA's payloads which require polar orbits fly on these orbiters. The NASA and the DoD have, over the years, maintained an in-depth liaison to assure the maximum interchange and common use of interfaces, operational concepts, flight and ground systems, as well as operations personnel. The value of this continuing effort is now apparent. Orbiters, tugs and ground equipment are largely interchangeable between the two launch sites as well as between NASA and DoD. This allows flexibility of payload flight assignment and has avoided many millions of dollars in dual developments.

Now that we have reviewed the functional elements of the payload activities at this Space Base of the Future, let us look at some of the features of the operational concept. As space veterans whose experience goes back to the pioneer programs like Apollo and Skylab, let us concentrate on some of the features and philosophies that appear to have changed the greatest amount. (Figure 4)

\section{Figure 4}

Features of the Concept

1. Clear and Simple Lines of Responsibility and Authority.

2. Criticality of Orbiter Turnaround Time.

3. Standardization of Interfaces.

4. A User Handbook System.

5. A Customer Orientation.

6. Premate Demonstration of Payload System Compatibility with the Orbiter and the Ground System.

\section{The Owner-Operator Concept.}

8. Reduced Number of Organizational Elements.

9. Cost of Failure Vis A Vis Cost of Flight Preparation Sensitivity.

1. Clear and Simple Line of Responsibility and Authority. Research and Development operations such as Apollo and Skylab required complex responsibility patterns and many problems necessitated complex committee actions. The opportunity to simplify these decision processes is a key cost and time saving result of the standardized, reusable hardware concept. Day-today operating decisions are made at a much lower organizational level. The number of people required to make a decision is proportional to the organizational level of the decision maker.

2. Criticality of Orbiter Turnaround Tine. A high orbiter utilization rate is key to the economic advantage of the reusable transportation system. Operational delays in the orbiter schedule also result in a day for day impact in the runout cost of subsequently assigned payloads.

3. Standardization of Interfaces. Manned Space Fiight has adopted this concept from the Airborne Science Program at Ames Research Center. This concept renders the configuration of reusable space hardware insensitive to the assigned mission, increases utilization of reusable olements by nearly an order of magnitude, and allows experimenters and other payload owners to design to a known fixed interface rather than one that is constantly changing. Orbiter to payload, ground system to payload and third stage to spacecraft are standardized interfaces. The payload carrier and sortie lab interface to experiments has been standardized in many instances.

4. A User Handbook System. A user Handbook System replaces ICD's, PSRD's, and AAPD-26's for payload interface and test control. This concept was adapted from NASA's umanned space programs and the Ames Airborne Science Program. The system is based on a Users Guide published by the operator of the reusable, standardized parts of the Space Transportation System, such as the Shuttle, Ground System, Experiment Carriers and Thind Stages.

5. A Customer Orientation. The primary mission of the shuttle operator has evolved from shuttle development into a transportation service. This has resulted in an enviroment that provides the experimenters a much more flexible and responsive enviromment than during the days when their experiment was secondary to booster development or lunar landing. The payload owner retains full responsibility for the performance of his hardware throughout the mission.

6. Premate Demonstration of Payload System Compatibility with the Orbiter and the Ground System. Due to the cost of delays to the orbiter schedule, a11 payloads are tested with simulated or duplicated orbiter and ground system interfaces.

7. The Owner-Operator Concept. This concept greatly reduces the transfer of responsibility from organization to organization during the life cycle of a payload. This concept was basic to major reductions in interorganizational paper and control systems. This concept was developed for NASA in a 1973 study by the Martin Marietta Corporation.

Assignment of responsibility for the total mission cycle to a single organization is the basis for this concept. The Shuttle Operator acts as a 
host to experimenters and for owners of payloads undergoing constant change and inprovement by the developer. The Shuttle operator is the owneroperator of payloads that are standardized and reusable.

8. Reduced Number of Organizational Elements. Many organizations that were required by a major developmental effort no longer exist. Examples of such organizations are middleman integrators, staff check and balance functions, and groups that administer the interorganization paperwork control systems. This organizational simplification has resulted in the more effective utilization of many very talented people.

9. Cost of Failure Vis A Vis Cost of Flight Preparation Sensitivity. As mentioned earlier, the depth and cost of payload preparation is a function of the dollar and safety cost of payload failure. As an example: If a mission can be repeated for 10 million dollars, expectancy of a payload failure is $5 \%$ and crew or orbiter safety is not involved, then it is not practical to spend $1 / 2$ million dollars to reduce failure expectancy to $2 \%$.

Now, back to Cocoa Beach and 1973 - We believe the development of many of the ideas expressed here will be necessary if the Space Shuttle is to truly open mankind's next frontier. Your ideas and criticisms are solicited during the continuing development of these concepts. 